\title{
Rankings acadêmicos internacionais nas mídias de duas universidades de pesquisa brasileiras
}

\author{
International academic rankings in the \\ medias of two brazilian research universities
}

\author{
Gladys Beatriz Barreyro ${ }^{1}$ \\ Poliana Pereira dos Santos ${ }^{2}$ \\ Flávio Batista Ferreira ${ }^{3}$
}

Resumo: Os rankings acadêmicos internacionais, criação do século XXI, têm se tornado uma frequente fonte de referência acerca da qualidade da educação superior para o grande público, apesar de receberem críticas variadas quanto a sua legitimidade e confiabilidade. Este texto apresenta os resultados de um estudo sobre os usos dos rankings em mídias impressas e eletrônicas de duas universidades brasileiras: a Universidade de São Paulo e a Universidade Estadual de Campinas. Através da análise das matérias, realizou-se uma caracterização das formas como os resultados dos rankings internacionais foram divulgados por estas universidades em suas mídias oficiais, de modo a buscar indícios de possíveis usos durante o período de 2013-2017. Verificou-se que eles são descritos, explicados e utilizados em diversas comparações. Embora os resultados obtidos pelas universidades nas classificações sejam comemorados, também há críticas e suas limitações são expostas, principalmente por acadêmicos ocupando cargos de gestão e por estudiosos da temática.

Palavras-chave: Rankings acadêmicos. Universidade. USP. UNICAMP. Mídias acadêmicas. 
Abstract: The international academic rankings, created in the 21st. Century, have become a frequent source of reference on the quality of higher education, despite being critiziced by their legitimacy and uses. This paper presents the results of a study on the uses of rankings in print and electronic medias of two brazilian universities: The University of São Paulo and the State University of Campinas. Articles about rankings published in the universities oficial medias during the period of 2013-2017 were selected and analizes in order to look fo their uses. It was found that they are identifies, explaindes and used in several comparisons. Despite the performances of the universities being celebrated, the rankings are also critiziced and their methodological limitations, exposed, mainly by academics who hold management positions and experts on the issue.

Keywords: Academic rankings. University. USP. UNICAMP. Academic media.

\footnotetext{
${ }^{1}$ Universidade de São Paulo | Programa de Pós-Graduação em Educação| São Paulo | SP |

Brasil. Contato: gladysb@usp.br. ORCID: http://orcid.org/0000-0002-2714-5811

${ }^{2}$ Universidade de São Paulo | Licenciatura em Ciências da Natureza | São Paulo | SP | Brasil. Contato: poliana.96@ hotmail.com. ORCID: https://orcid.org/0000-0003-4952-2697

${ }^{3}$ Universidade de São Paulo | Programa de Pós-Graduação em Educação | São Paulo | SP | Brasil. Contato: flavio.ferreira@alumni.usp.br. ORCID: https://orcid.org/0000-0003-0031-4803
}

- Recebido em: 10 de agosto de 2020

- Aprovado em: 13 de maio de 2021

DOI: http://dx.doi.org/10.1590/S1414-40772021000300010

Este é um artigo publicado em acesso aberto sob uma licença Creative Commons https://creativecommons.org/licenses/by-nc/4.0/ 


\section{Introdução ${ }^{1}$}

Os rankings acadêmicos ou rankings universitários são tabelas de classificação ordenada de instituições de educação superior, conforme o seu desempenho, medido através de critérios definidos pelos elaboradores de cada publicação. As primeiras experiências de ranqueamento de universidades remontam ao final do século XIX, porém foi a partir de 2003 que a comparação, classificação e ordenamento de universidades passou a ser internacional. Dentre os rankings internacionais, os mais conhecidos e influentes são o Academic Ranking of World Universities (ARWU), publicado pela Shangai Jiao Tong University desde 2003, o The Times Higher Education World University Ranking (THE), mantido pelo jornal inglês The Times e o QS World's University Ranking (QS), da Quacquarelli Symonds. Além das listas globais, cada um desses rankings mantém suas séries de classificações temáticas e/ou regionais. Eles comparam as universidades em escala global a partir de variados indicadores, escolhidos dentre informações disponíveis, variando a metodologia entre um ranking e outro.

As diferentes metodologias e técnicas usadas para a produção dos rankings recebem críticas, desde a não produção de indicadores próprios e o uso apenas de informações disponíveis, a exclusividade das citações em língua inglesa que beneficia os países anglosaxões, até o número de prêmios Nobel da instituição que limita a instituições com abundantes recursos, especialmente inglesas e estadunidenses (HARVEY, 2008). Apesar das críticas, os rankings geram impactos nas instituições de educação superior (HAZELKORN, 2010) e demonstram capacidade de remodelar o cenário do ensino superior em termos de diversidade (STENSAKER; KEHM, 2009).

A escolha dos rankings acadêmicos internacionais como objeto de pesquisa justifica-se nos estudos sobre a governança multiescalar da educação, desenvolvidos por Roger Dale e Susan Robertson. Segundo esses autores, a globalização neoliberal do final do século XX redefiniu funções dos estados nacionais, que no caso da educação deslocou a abrangência da governança para o nível global. Com isso, as ferramentas da modernidade, que tratam as políticas de educação apenas como uma questão nacional tornaram-se insuficientes para a compreensão dos fenômenos. Dale (2005) considera a política supranacional como essa nova escala, diferente dos estados. Para o autor, o Estado mantém a sua importância por estar

\footnotetext{
${ }^{1} \mathrm{O}$ texto é resultado da pesquisa desenvolvida por G. Barreyro em semestre sabático (1/2018) no Instituto de Estudos Avançados (IEA) da Universidade de São Paulo, que estudou os rankings acadêmicos internacionais nas mídias escritas da USP e da Unicamp. Ainda, recebeu subsídios da pesquisa em desenvolvimento Internacionalização da educação superior: usos e impactos dos rankings acadêmicos internacionais, nas universidades "de pesquisa" no Brasil, coordenado por G. Barreyro, com apoio do CNPQ. (Processo 433761/2018-0)
} 
envolvido na rede de relações supranacionais, além de responderem pela aplicação das políticas supranacionais em ações no âmbito nacional (DALE, 2009). São os estados os encarregados de coordenar o trabalho de governar (DALE, 2005). Nessa governança escalar, outras instituições adquirem importância além dos estados nacionais (ROBERTSON; DALE, 2015).

Os rankings acadêmicos internacionais são um exemplo de governança escalar, pois atuam na escala global, focando na pesquisa das universidades, com impactos diretos da escala global à institucional, mudando as instituições. Os rankings têm propósitos amplos, sociais e políticos, criados em um local determinado e que rapidamente se desenvolvem transformando os contextos de origem e de destino (ROBERTSON; OLDS, 2011).

Este estudo considerou que uma das formas de compreender como as instituições reconhecem os rankings internacionais, como elas apropriam-se deles e fazem uso de seus resultados é expressa por sua comunicação institucional. Este olhar também permite perceber as contradições no nível institucional que podem evidenciar resistências e tensões nas relações de poder. A pesquisa focou duas universidades "de pesquisa" 2 brasileiras: a Universidade de São Paulo (USP) e a Universidade de Campinas (Unicamp). Essas instituições foram escolhidas considerando as suas posições nos diferentes rankings. O estudo analisa as matérias jornalísticas sobre os rankings acadêmicos internacionais, divulgadas pela USP e pela Unicamp, identificando seus usos em duas mídias acadêmicas: o Jornal da USP e o Portal da Unicamp. Apresenta resultados de pesquisa exploratória bibliográfica e documental, considerando-se como documentos o corpus coletado após a leitura das mídias no período de 2013 a 2017. O material foi analisado a partir de categorias surgidas após a leitura das matérias, em interação com o referencial teórico.

\section{Excelência, atratividade, competitividade, seletividade e distinção: as universidades frente aos valores do mercado mundial do conhecimento}

Os rankings acadêmicos internacionais foram incorporados por diferentes setores e atores da sociedade - universidades, governos, organismos internacionais, instituições financeiras, indústrias, estudantes, e outros - que passaram a utilizar não apenas os seus

\footnotetext{
${ }^{2} \mathrm{O}$ uso de aspas não indica dúvida sobre as atividades de pesquisa desenvolvidas por essas universidades, que são responsáveis por parte significativa da produção acadêmica e científica nacional, mas os limites do uso da expressão "universidades de pesquisa", amplamente feito no meio acadêmico para diferenciar universidades. Esse uso é especialmente problemático no Brasil, em que o Art. 207 da Constituição Federal estabelece o princípio de indissociabilidade entre ensino, pesquisa e extensão, além do fato de não existir um sistema oficial de classificação de instituições de educação superior pela natureza de suas atividades, como é o caso da Carnegie Classification of Institutions of Higher Education nos Estados Unidos.
} 
resultados, mas também alguns pressupostos da constituição de suas metodologias como parâmetros para as políticas, para as escolhas e para a gestão da educação superior.

A visibilidade e a influência que os rankings acadêmicos passaram a ter podem ser explicadas pela aderência entre os seus fundamentos e as políticas neoliberais que orientaram e ainda orientam projetos e programas educacionais e que concebem a educação como um serviço e o conhecimento como uma mercadoria. Os valores que são promovidos por essas tabelas de classificação disseminam e fortalecem práticas que configuram um mercado mundial do conhecimento (HAZELKORN, 2010).

A criação do Acordo Geral de Comércio e Serviços (GATS), em 1996, alterou o panorama das políticas e estratégias que os estados nacionais geravam para abordar a questão da qualidade da educação superior. Ao incluir à educação como um serviço comercial, o GATS é uma síntese das transformações que a educação superior estava sofrendo e que mudaram a sua função de prover quadros profissionais para os estados nacionais para sua direta participação na economia globalizada (BARREYRO, 2017).

A qualidade da educação superior até então era aferida, desde os anos de 1980, por variantes da acreditação estadunidense surgida no século XIX, desenvolvida em nível nacional com a intervenção ou não do estado nos seus processos. Com a globalização, surgem políticas regionais de acreditação como a realizada pela União Europeia e suas agências no marco do Processo de Bolonha. A criação do Ranking de Shangai, como ficou conhecido o ARWU, inovou na utilização de uma ferramenta comparativa centenária nacional (os rankings acadêmicos) ampliando a abrangência da avaliação para o nível global e no uso da comparação como método para focar um aspecto específico da qualidade: a excelência, destacando apenas as instituições do topo.

Assim, o surgimento dos rankings acadêmicos internacionais é paralelo ao papel central da educação superior quanto à provisão de capital humano, para a geração de novos conhecimentos e de transferência tecnológica baseados na circulação internacional de talentos (HAZELKORN, 2010).

Os rankings acadêmicos internacionais contribuem para divulgar a concepção de Universidade de Classe Mundial (UCM): instituições de pesquisa, globais, que concentram professores e alunos altamente talentosos, amplos recursos e governança flexível (SALMI, 2009). Além disso, valorizam a orientação de pesquisas à aplicação direta e em determinadas áreas do conhecimento, favorecendo um tipo de inovação que é de interesse dos setores produtivo e financeiro, com características que são as priorizadas pelos indicadores que os compõem. As universidades que concentram as melhores condições para o reconhecimento 
como UCM são peças chave da reforma global da educação superior, pelo potencial que essas instituições têm de favorecer esta inovação que se traduz na criação de novos produtos e serviços.

As instituições que obtêm melhores resultados nos rankings são aquelas em que a pesquisa é muito importante, priorizam a pós-graduação, são meritocráticas e elitistas, atraindo os melhores estudantes e docentes, que ministram poucas horas de aula, pois priorizam a pesquisa (ALTBACH, 2011).

As UCM cumprem um papel na divisão do trabalho acadêmico mundializado, garantindo aos países centrais do capitalismo a manutenção de instituições do topo das listas de classificação, voltadas à formação para o trabalho complexo e para a produção científica e tecnológica original, restando aos demais países a formação técnica instrumental e a pesquisa voltada à adaptação e incorporação de tecnologias (SILVA JÚNIOR, 2017). Em países como o Brasil, o modelo de UCM é induzido com o objetivo de criar alguns poucos centros de excelência, que possam garantir o processo de transferência de tecnologia e também a mobilidade de unidades das grandes corporações, que mantém suas sedes nos países de capitalismo mais desenvolvido (THIENGO, 2018).

A diferenciação criada a partir dos rankings e pela concepção de UCM permite a distinção entre as universidades que realizam pesquisa de forma intensa e as múltiplas possibilidades de prover serviços relacionados com a formação de pessoas em nível superior. Esta separação favorece a transnacionalização das atividades de ensino superior como um mecanismo de ampliar as receitas de universidades estrangeiras. Assim, a educação à distância transnacional, a criação de franquias de universidades, com a venda do direito de uso de sua marca por empresas de outros países, a mobilidade estudantil e acadêmica, beneficia com as comparações internacionais para escolha de consumidores desses serviços.

As características que distinguem uma instituição como uma UCM impõem a competitividade como prática acadêmica. Os rankings retratam o campo global da educação superior como uma competição entre diferentes instituições por "professores e alunos altamente talentosos" (SALMI, 2009, p. 6) e por recursos que favoreçam o reconhecimento de sua excelência. Nesse contexto, os professores e alunos talentosos são aqueles que demonstram as qualificações adequadas para a produção dos indicadores de excelência dos próprios rankings. Os recursos abundantes são reconhecidos como investimento, uma vez que são aplicados seletivamente após a demonstração do seu potencial de retorno em produtos e serviços. Segundo Erkkilä (2014), as universidades de maior prestígio tornam-se modelos ideacionais, fazendo com que os rankings estejam intimamente ligados à convergência global das políticas de 
educação superior e inovação. As finalidades das universidades são submetidas a um reducionismo economicista, uma vez que seus resultados são valorizados por seu potencial econômico, muitas vezes motivado pelos ganhos percebidos para a economia baseada no conhecimento (ERKKILÄ, 2014).

Ao fomentar e intensificar a competitividade entre instituições e ao incluir a reputação acadêmica como um critério destacado em suas metodologias, os rankings internacionais arrastaram instituições históricas e reconhecidas para o mercado mundial do conhecimento, transformando-as em organizações que se movem estrategicamente na busca de melhores posições (HAZELKORN, 2010).

Em contraposição, é necessário destacar que os efeitos e impactos reais dos rankings sobre as instituições são menos uniformes e conclusivos do que a sua incorporação discursiva pelas universidades. Isso destaca a importância do contexto institucional e das tradições na compreensão dos efeitos dos rankings globais sobre as universidades. Os impactos reais dessas classificações são geralmente indiretos. Além disso, é provável que os seus resultados sejam condicionados pelas tradições institucionais, marcando também uma abertura para resistir a mudanças exclusivamente para atender aos critérios das listas (ERKKILÄ, 2014).

A sustentação de uma concepção da educação como um serviço e do conhecimento como uma mercadoria no mercado global é feita através da indução de valores como a excelência, a atratividade, a competitividade, a seletividade e a distinção, que evidenciam um dos mecanismos de uma governança global da educação superior. Considerando que a disseminação desses valores encontra resistência na esfera institucional, a análise das mídias de USP e Unicamp foi feita de modo explicitar tanto as apropriações discursivas que legitimam os resultados dos rankings como as críticas que sinalizam para as suas limitações.

\section{As universidades brasileiras nos rankings internacionais}

Os rankings acadêmicos internacionais são um sistema de classificação de universidades que compara a partir de variados indicadores universidades na escala global. Dentre os Rankings internacionais os mais considerados são o ARWU, Academic Ranking of World Universities, da Shangai Jiao Tong University atuando desde 2003; o The Times Higher Education World University Ranking, desenvolvido pelo jornal inglês The Times e o QS World's University Ranking. (BARREYRO, 2018; SANTOS; NORONHA, 2016; PILATTI; CECHIN, 2018). Tais rankings se utilizam de um conjunto de indicadores, que são escolhidos pelos elaboradores dos rankings dentre informações disponíveis e variando entre um ranking e outro. Basicamente, os indicadores usados por esses rankings para avaliar as instituições são: 
publicações em inglês (especialmente nas revistas Nature e Science), número de prêmios Nobel na instituição, impacto das citações de artigos, fundos destinados à pesquisa, relação do número de discentes por docente, número de docentes estrangeiros e questionário aplicado a acadêmicos sobre reputação (BARREYRO, 2018) ${ }^{3}$.

Dentre os três rankings considerados principais, “[...] do ponto de vista da representatividade das universidades brasileiras os rankings internacionais, pode-se dizer que o QS demonstra ser o ranking mais “inclusivo"' (SANTOS; NORONHA, 2016, p. 212).

Várias universidades brasileiras ocupam posições nos rankings acadêmicos internacionais. ${ }^{4}$ Nos três rankings antes mencionados a USP e a Unicamp obtiveram as melhores posições, como mostra a tabela:

Tabela 1 - Posições das IES brasileiras nos primeiros lugares nos rankings internacionais ARWU, THE e QS. (2018)

\begin{tabular}{cccc}
\hline Universidades brasileiras & ARWU/TSE & THE (Ranking geral) & QS 2019 \\
& $\mathbf{2 0 1 7}$ & $\mathbf{2 0 1 8}$ & 118 \\
\hline USP & $51-200$ & $251-300$ & 204 \\
\hline Unicamp & $401-500$ & $451-500$ & 361 \\
\hline UFRJ & $301-400$ & $601-800$ & 491 \\
\hline Unesp & $301-400$ & $601-800$ & 464 \\
\hline Unifesp & $500+$ & $451-500$ & \\
\hline
\end{tabular}

Fonte: BARREYRO, G. B.; FERREIRA, F. B. Internacionalização: Universidades de Classe Mundial e Rankings Acadêmicos. In: OLIVIERA, J. F.; LIMA, D.C.B.P (org.). Educação Superior e PNE (20142024): expansão e qualidade em questão. Brasília: ANPAE, 2019. p. 155-171.

Mas as duas instituições vem ocupando essas posições desde surgimento dos rankings internacionais, como o ARWU, o THEWorld, THE Latin America, QS Latin America, Webometrics, Scimago Institutions Rankings World, Scimago Institutions Rankings Ibero (SANTOS, 2018), entre outros.

As universidades veem se utilizando de suas posições favoráveis nos rankings para divulgação. Segundo Laus e Magro (2013, p. 10): “é observável um crescente entusiasmo daquelas melhor avaliadas em dar publicidade aos resultados alcançados".

Leite e Genro (2012) afirmam que os rankings são considerados pauta de marketing, uma divulgação das posições alcançadas pelas instituições, como exemplo, a posição entre as dez primeiras.

\footnotetext{
${ }^{3}$ Para detalhes acerca da criação desses rankings e os indicadores que os compõem, ver Barreyro e Ferreira (2019).

${ }^{4}$ Para mais informações, consultar Santos e Noronha, (2016); Pilatti e Cechin, (2018) e Barreyro e Ferreira (2019).

${ }^{5}$ Dados disponíveis nos sites dos rankings em julho de 2018.
} 


\section{Os rankings nas mídias das universidades}

A escolha das mídias universitárias deve-se à possibilidade de explorar documentalmente o objeto de estudo e é uma primeira etapa de uma pesquisa maior que estuda os usos e efeitos dos rankings acadêmicos internacionais em universidades ditas de pesquisa no Brasil. As mídias permitem uma aproximação ao posicionamento das universidades respeito do objeto e aos usos e funções que os rankings adquirem na difusão mediática de notícias.

O Jornal da USP é parte integrante do Portal da USP e é um jornal digital da Universidade de São Paulo, veiculado neste formato desde maio de 2016, disponível pelo link: http://jornal.usp.br/, pois anteriormente era divulgado apenas na versão impressa ${ }^{6}$. As matérias publicadas são de autoria da Superintendência de Comunicação Social da USP, trazendo notícias diárias sobre a Universidade de São Paulo. Está dividido em temas, estes são: Atualidades, Ciências, Cultura, Educação, Institucional, Universidade e Tecnologia, além de permitir acesso à Rádio USP e TV USP. Os campos temáticos que apresentam maior frequência de notícias em relação aos Rankings Universitários são: o Institucional e o Atualidades.

O Portal da Unicamp existe desde 1994 e é a mídia digital pertencente à Universidade Estadual de Campinas. O Jornal da Unicamp está associado diretamente ao Portal, vinculado no meio digital a partir de dezembro de 2016. O link para acesso a este portal é: http://www.unicamp.br/unicamp/.

O Portal apresenta a informação organizada em quatro quesitos: Área de saúde, Faculdades e Institutos, Ingresso, Informações para; todos esses voltados a questões ligadas estritamente à Universidade. Ainda apresentam-se as temáticas: A Universidade, Ensino, Pesquisa, Relações com a Sociedade, Mídia \& Comunicação.

As matérias foram selecionadas pelo portal GOOGLE (google.com.br) de acordo com as palavras chaves: PORTAL UNICAMP RANKINGS / JORNAL USP RANKINGS, sendo utilizada a ferramenta configuração avançada que permitiu filtrar as matérias existentes no site sob o domínio jornal.usp.br e unicamp.br.

Foram encontradas 107 matérias no Jornal USP que utilizam a palavra ranking, identificadas pelo filtro de pesquisa. Destas, 40 são matérias com foco integral na temática ranking, seja porque tratam sobre os rankings propriamente ditos ou divulgam posições nos rankings.

\footnotetext{
${ }^{6}$ As versões anteriores de 2013 a 2016 foram solicitadas aos responsáveis pelo Jornal e disponibilizadas no endereço https://www.usp.br/jorusp/.
} 
Quanto à Unicamp, foram encontradas 49 matérias no Portal Unicamp que utilizam a palavra ranking, identificados pelo filtro de pesquisa. Destas, 10 são matérias com foco integral na temática ranking, seja porque tratam dos rankings propriamente ditos ou divulgam posições nos rankings.

Depois de uma primeira leitura das matérias publicadas nas mídias da USP e da Unicamp, foram selecionadas para análise, aquelas que tratam integralmente sobre os rankings acadêmicos internacionais. Sendo, $38^{7}$ matérias do Jornal da Usp e 10 do Portal Unicamp.

As matérias selecionadas são de diversos tipos, predominando as curtas, informativas, especialmente no Portal da Unicamp, mas também se encontram matérias mais extensas, com a voz de algum membro da universidade. Excepcionalmente, há matérias analíticas em que se consultam especialistas, dentre elas pessoas que fizeram tese sobre rankings. Muitas das matérias acompanham fotografias, principalmente de algum espaço universitário, ou de impressos dos próprios rankings. Algumas também incluem tabelas e inclusive links, em que pode ser verificada a lista de instituições ranqueadas e sua posição.

Os rankings referenciados nas matérias do Jornal da USP foram os seguintes:

THE América Latina (sic); THE Scimago institutions rankings; THE World reputation ranking ;THE BRICS and emerging economies ranking; QS World ranking university; QS World university ranking by subject; QS University ranking Latin America; QS University ranking BRICS; QS Graduate employability ranking; U.S News Best Global Universities (US News and World report); National Taiwan University Ranking; ARWU; ARWU Global ranking for academic subject ; Center for university rankings by subject; Ranking web de universidades (Webometrics); National Taiwan University Ranking e Performance ranking of scientific papers for World Universities (Nat taiwan universitiy). No Portal da Unicamp, os rankings citados foram THE World University Ranking; THE Reputation Latin America; US News and World Report; ARWU; QS; QS BRICS; Webometrics; Leiden ranking e Ranking de universidades jovens com até 50 anos de existência. Os nomes dos rankings são escritos em inglês sem tradução; algumas vezes no título da matéria aparece uma menção em português ou no interior da matéria há algum esclarecimento, mas parece estar naturalizada a denominação em inglês.

A seguir serão apresentadas e analisadas as formas de abordagem dos rankings nas matérias selecionadas visando explicar o seu uso. São apresentados exemplos extraídos das mídias para ilustração.

\footnotetext{
${ }^{7}$ Foram eliminadas duas matérias que tratam de rankings nacionais por não ser foco da pesquisa.
} 


\title{
Apresentação e descrição
}

Em diversas matérias os rankings internacionais são explicados para contextualizar, em geral, os resultados alcançados pela instituição. Indica-se quem o elabora e são listados os critérios técnicos, ou seja os indicadores que o compõem e o peso que eles têm na sua composição. A estratégia, muito comum, pode observar-se, por exemplo em:

\begin{abstract}
Para compor o ranking são avaliados os itens: reputação acadêmica (30\% da nota) pesquisa com professores sobre as universidades que estão produzindo o melhor trabalho em sua área de especialização acadêmica; reputação do empregador (20\%) - entrevistados identificam as instituições em que preferem recrutar; relação do corpo docente / aluno $(20 \%)$ - relação entre docentes em tempo integral e alunos matriculados; artigos por docente (10\%) - número de artigos publicados por docente na base de dados Scopus; proporção de docentes com doutorado (10\%); citações por artigo $(5 \%)$ - utiliza a base de dados Scopus com o número médio de citações por artigo publicado; professores estrangeiros $(2.5 \%)$ - calcula a proporção de docentes da universidade que são de outra nacionalidade; alunos estrangeiros $(2.5 \%)$ - alunos estrangeiros (2.5\%) - calcula a proporção de alunos intercambistas (BRITO, 2016a, grifo da autora).
\end{abstract}

\section{Divulgação dos resultados}

É interessante observar as formas de divulgação dos resultados obtidos pelas instituições nos rankings que envolvem diversas estratégias. Uma delas é a objetiva/descritiva em que se explica a posição que ocupa a instituição, porém é a forma menos usual de apresentação, como na seguinte oração: "De acordo com a relação, que engloba 77 países, a Universidade está situada no grupo que reúne as posições 401 a 500, [No World University Rankings THE]" (ALVES FILHO, 2017b). No exemplo que não é o mais comum, percebe-se a informação de forma objetiva em que se colocam informações de contexto: os países que participam e o lugar real: a posição 401 a 500. Contudo, é muito mais frequente especialmente em manchetes, o uso de sintagmas como: " $x$ é a melhor universidade latinoamericana segundo o ranking $y$ ”, assim como de outras expressões tais como: "USP sobe 23 posições e alcança a melhor classificação no QS Ranking." (USP, 2016); “Unicamp mantém posição no ranking global de universidades." (ALVES FILHO, 2017b); “Unicamp sobe no ranking QS” (VILLEN, 2017) e:

\footnotetext{
A USP foi a única universidade brasileira e latino-americana a figurar nessa classificação, ocupando a posição entre 81-90, o que representa uma ligeira queda em relação ao ano passado, em que a instituição estava na posição entre 61-70. [Resultados obtidos no 2014 World Reputation Ranking do THE (CALDEIRA, 2014a).
}

A anterior, que chamamos de estratégia de competição, não foca no resultado per se, na posição. O resultado aparece como melhoria (subida), descida ou manutenção, gerando a 
impressão de que há ações anuais que geram mudanças institucionais, quando desde as instituições não se compartilha dessa visão.

Os exemplos anteriores supõem comparação com resultado anterior e uma melhoria (ou manutenção) de posição. Contudo, essa afirmação é questionável porque os rankings mencionados nos fragmentos anteriores consideram a reputação. Assim, o Quaquarelli Symonds World University Ranking inclui seis variáveis para ranquear as instituições, sendo duas delas reputacionais: a reputação acadêmica e a reputação junto aos empregadores. A primeira delas tem $40 \%$ de peso no ranking e a segunda $10 \%$. Para obter essa informação, a QS consulta professores de mundo todo que desejem responder à consulta feita por email. Isto faz com que as pessoas possam participar em algum ano e não em outro; portanto os resultados não podem ser comparados de ano para ano. Ou seja, nenhuma instituição sobe ou baixa nesse ranking, ela simplesmente pode mudar a cada ano, porque se tornou mais conhecida por diversos motivos, inclusive por efeito da divulgação desse mesmo ranking. Já o THE Reputation Rankings é baseado em respostas de acadêmicos de diversos países, ou seja, totalmente focado em reputação, critério também empregado em outros rankings.

Comparações também são feitas com outras instituições, como se mostra a seguir:

No mundo inteiro, apenas quatro instituições de ensino superior estão à frente da USP na área de ciências agrárias, de acordo com o recém-divulgado ranking US News Best Global Universities (Melhores Universidades Globais), produzido pela editora norteamericana US News \& World Report (HEBMULLER, 2014).

Mais outras comparações são feitas com instituições da mesma ou outra região geográfica. A América Latina é frequentemente mencionada nas matérias das duas universidades, especialmente quando se trata de rankings específicos sobre as instituições da região, tais como QS University ranking Latin America, Times Higher Education Latin America e THE Reputation Latin America. Esses rankings não são elaborados na América Latina, mas são produto dos rankings internacionais mais influentes, e desconsideram outras informações relevantes à região que poderiam compor indicadores diferentes dos priorizados. $\mathrm{O}$ exemplo seguinte reforça o lugar de destaque na região, com informações de um ranking global que foi criado considerando apenas as instituições latinoamericanas:

Na segunda-feira, 13 de junho, foi divulgado o QS University Rankings: Latin America 2016 sobre o desempenho das universidades da América Latina. Assim como no ano passado, a USP ficou novamente em primeiro lugar. Essa é segunda vez que a Universidade se destaca em rankings regionais. No dia 26 de maio, a Times Higher Education (THE), outra instituição que analisa as performances de universidades, havia apontado a USP como a mais prestigiada da América Latina. [...] Também aparecem no top 10 latino-americano a Pontificia Universidad Católica de Chile $\left(3^{\circ}\right)$, Universidad Nacional Autónoma de México (4º), a Universidad de Chile (6 ${ }^{\circ}$ ), Instituto 
Tecnológico e de Estudos Superiores de Monterrey $\left(7^{\circ}\right)$ também no México, Universidad de Los Andes $\left(8^{\circ}\right)$ e Universidad Nacional de Colombia $\left(10^{\circ}\right)$, ambas nesse país (BRITO, 2016b, sublinhado da autora).

Além de comparações com América Latina, ressalta-se as do grupo de países BRICS (Brasil, Rússia, Índia, China e África do Sul), pois existe um outro ranking dedicado a eles:

A Unicamp assumiu a liderança do ranking QS Brics 2017/2018 entre as universidades brasileiras, conforme relatório divulgado nesta quinta-feira (23) pela consultoria internacional Quacquarelli Symonds (QS), responsável pela avaliação. A relação considera 300 universidades do Brasil, Rússia, Índia, China e África do Sul, os chamados Brics, países com economias emergentes. A Unicamp aparece na $12^{\mathrm{a}}$ classificação no ranking, seguida pela USP, que está em $13^{\circ}$ lugar, empatada com a Saint Petersburg State University (Rússia) (ALVES FILHO, 2017a).

Também, ocupam destaque na estratégia de comparação, as realizadas com outras instituições brasileiras:

A USP ficou em $10^{\circ}$ lugar e é a universidade brasileira com a melhor colocação. Em 2015, a Universidade ocupou o nono lugar. A segunda instituição brasileira a aparecer na lista é a Unicamp, na $12^{\mathrm{a}}$ posição, seguida da Universidade Federal do Rio de Janeiro (UFRJ), em $29^{\mathrm{a}}$. A Universidade Estadual Paulista (Unesp) ficou em $36^{\circ}$ lugar; a Universidade Federal de São Paulo (Unifesp), em $45^{\circ}$; e a Pontifícia Universidade Católica do Rio de Janeiro (PUC-RJ) e a Universidade Federal de Rio Grande do Sul (UFGRS) dividem a $46^{\mathrm{a}}$ posição (BRITO, 2016a).

O Brasil domina o ranking, com cinco instituições entre as dez melhores colocadas. A USP é a primeira, encabeçando a lista. Depois vêm Unicamp, UFRJ (quinta posição), PUC-Rio (sexta), e UFMG (sétima). A Unesp ocupa o $11^{\circ}$ lugar. Ao todo, das 50 universidades ranqueadas, 23 são brasileiras. O Chile é o segundo país mais representado, com 11 instituições, seguido do México, com oito (ORSI, 2016, sublinhado no original).

Com outras instituições estrangeiras (nem brasileiras, nem latinoamericanas) também são feitas comparações:

A USP é a universidade latino-americana melhor colocada no World University Ranking 2017-2018, divulgado hoje, dia 5 de setembro, pela consultoria britânica Times Higher Education (THE). No topo da lista, lideram as universidades britânicas de Oxford ( $1^{\circ}$ lugar) e Cambridge $\left(2^{\circ}\right)$, seguidas pelas norte-americanas Universidade de Stanford e Instituto de Tecnologia da Califórnia (Caltech), ambas empatadas na $3^{\text {a }}$ colocação. Das dez primeiras posições, seis são norte-americanas, três são britânicas e uma é suíça.No mesmo grupo do ano passado, entre as posições 251-300, a USP se iguala a instituições como a Universidade do Estado da Carolina do Norte (EUA), a Universidade de Surrey (Reino Unido) e o Instituto de Tecnologia de Tóquio (Japão) (YAMAMOTO, 2017, grifo no original).

Um novo ranking divulgado esta semana pelo QS coloca a Unicamp como a segunda melhor Universidade da América Latina e à frente da USP, a terceira colocada. A Pontíficia ( sic) Universidade Católica do Chile lidera. A Unesp é a décima colocada (RANKING..., 2017).

As estratégias retóricas anteriores podem aparecer juntas, como no fragmento seguinte em que aparece a objetiva, de explicar a posição, com a de destaque positivo em que se 
acrescenta a informação de que a instituição está entre as primeiras, no caso 100 instituições do mundo. Ainda aparece a comparação com, no caso, a América Latina:

Divulgado em março, o 2014 World Reputation Ranking colocou a USP entre as cem universidades com a melhor reputação em todo o mundo. A USP ficou na posição 8190. É a única representante do Brasil e de toda a América Latina entre as cem universidades com melhor reputação (CALDEIRA, 2014b).

Assim, a comparação com outras instituições, que está na concepção mesma dos rankings fomenta a competição constante, a corrida pela excelência (HAZELKORN, 2010, THIENGO, 2018). Também a comparação com outras instituições, especialmente as instituições estrangeiras de países desenvolvidos, legitima a instituição nacional e, embora ela não consiga as melhores colocações, o fato de participar do mesmo jogo a valoriza. Contudo, essa comparação internacional pode virar uma faca de dois gumes, considerando recentes ataques às universidades pelo Ministério da Educação nacional e alguns setores da sociedade brasileira.

\section{Causas do resultado}

Em algumas matérias apela-se a explicação ou justificativa dos resultados obtidos pela instituição num determinado ranking. Geralmente, o porta-voz é um alto dirigente da instituição, como reitor ou diretor de unidade. Nos fragmentos a seguir tanto a história da instituição como decisões feitas, explicam esses resultados:

O ex-reitor da Unicamp, J.T. Jorge afirma: “Administrar, principalmente em épocas de crise e escassez de recursos, é fazer opções. Fizemos aquelas que nos pareceram fundamentais para preservar a qualidade da universidade. Os resultados demonstram que agimos corretamente" (JORGE, 2017). Ainda, o diretor da Esalq, José Vicente Caixeta Filho manifesta: “Tudo isso não é fruto de um trabalho institucional de curto ou médio prazo. É um trabalho de excelência desenvolvido há 113 anos" (HEBMULLER, 2014). E a coordenadora geral da Unicamp, Teresa Dib Zambon Atvars, afirma: "Esse resultado é consequência do desenvolvimento e do amadurecimento da instituição, fruto da qualidade dos trabalhos que aqui são realizados" (VILLEN, 2017).

Os fragmentos anteriores, ao afirmar a gestão e o trabalho contínuo, contrapõem-se com o imediatismo dos rankings que sugerem, pela mudança de posições, que as instituições aplicam melhorias ano após ano. 


\section{Espelho, espelho meu}

Frequentemente, nas matérias analisadas são achadas expressões de autoelogio e comemoração pelos bons resultados obtidos. As instituições parecem ter reconhecida sua atuação, sendo que o resultado as legitima. Quem comemora é o jornalista autor da matéria ou algum membro da instituição: "Não há nenhuma universidade no mundo, nos últimos 20 anos, que tenha dado à sociedade um presidente da República, dois ministros da Educação, um ministro da Cultura, um porta-voz da Presidência e um prefeito da cidade de São Paulo" (NAOE, 2016b) afirma o professor Safatle da USP. "Os bons resultados da USP vêm se repetindo nas diferentes e independentes classificações, comemora o reitor Marco Antonio Zago" (CASTRO, 2015) é outra mostra de satisfação na mesma instituição. Igual que: "Esse resultado coloca a USP no grupo formado por 1\% das melhores instituições" (YAMAMOTO, 2017).

No seguinte trecho, percebe-se uma variante na comemoração ao envolver também todo o sistema das três universidades paulistas e o gasto com a universidade pública, quando a Unicamp ficou em melhor posição que a USP;

A Unicamp aparece na $12^{a}$ classificação no ranking (QS BRICS 2017/2018), seguida
pela USP, que está em $13^{\circ}$ lugar [...] O resultado do QS Brics foi recebido com
satisfação pelo reitor Marcelo Knobel. "O resultado de mais um ranking consolida a
posição da Unicamp no cenário da educação superior mundial, mostrando mais uma
vez a força do sistema público de educação do estado de São Paulo, e a importância
de a sociedade investir em universidades públicas de qualidade", analisou o dirigente"
(ALVES FILHO, 2017a).

O mesmo procedimento repete-se: "ERanking QS coloca universidades paulistas no TOP 10" (RANKING..., 2017).

\section{Visões críticas aos rankings}

Além das comemorações, parecem também nos textos analisados, diversas opiniões que questionam os rankings ou aspectos deles, como as que focam nos indicadores, no tipo de instituição ou em razões políticas, coincidindo assim com tópicos apresentados na literatura acadêmica nacional e internacional.

Sobre os indicadores uma das críticas recorrentes é acerca de serem apenas os disponíveis, o que traz limitações, como afirma Solange Maria dos Santos:

A ausência de fontes de informação que permitam coletar adequadamente dados sobre as atividades das universidades faz com que essas intuições sejam classificadas com base em atividades que podem ser medidas, não com base nos indicadores de atividades que se deseja medir", avalia a pesquisadora (NAOE, 2016a). 
Outras análises, feitas sobre a seleção de indicadores, principalmente no Jornal da USP, focam nas diferenças entre disciplinas e na padronização que os rankings fazem sem levar em conta essas diferenças:

Uma variável que indiretamente acaba sendo deixada de fora pelos rankings é a pesquisa em áreas do conhecimento muito fortes da USP, como a agronomia. Ela não possui tanto destaque simplesmente porque as atividades agrícolas pesquisadas têm mais importância em âmbito regional, e não são tão citadas lá fora. [ ...] “...como a temática não é internacionalmente interessante, as bases de dados não a valorizam", lamenta Anderson Santana, chefe da Divisão de Gestão de Projetos do Departamento Técnico do Sistema Integrado de Bibliotecas (SIBi) da USP (CAIRES, 2016).

O tempo que leva para uma pesquisa de humanas ser feita, e um texto produzido, também é muito maior que para as áreas de exatas e biológicas. "Há pesquisadores de biológicas que produzem um artigo por mês - isso não existe na área de humanas, que envolve mais reflexão. Se um artigo de biológicas demora cinco anos para atingir o ápice em citações, um da área de humanas talvez demore dez, porque tem um tempo maior de maturação", explica o bibliotecário [Anderson Santana] (CAIRES, 2016).

Justin Axel-Berg, autor de uma dissertação sobre rankings analisa:

Medicina tropical, que é outro ponto forte da USP, não consegue ganhar o mundo, a menos em casos excepcionais, como a epidemia recente de zika que gerou preocupação também fora das nossas fronteiras. Aqui também começa a ocorrer por parte dos rankings uma ampliação de escopo para abranger esses campos do conhecimento mas, novamente, incipiente (CAIRES, 2016).

Mudanças nos indicadores coletados, também são mencionadas:

Estamos analisando o resultado obtido pela Unicamp em relação à mudança dos critérios do ranking da THE. Como bem destacado pelos organizadores, tais mudanças tornam qualquer comparação desses resultados em relação aos rankings anteriores pouco significativa", disse o coordenador-geral da Unicamp, professor Alvaro Crósta (ORSI, 2015).

Quanto ao tipo de instituição, diversos entrevistados mencionam que os rankings pela seleção de informações, acabam beneficiando às universidades de pesquisa, desconsiderando os benefícios das instituições ao seu entorno econômico, como mostram os fragmentos seguintes:

Você não pode comparar uma universidade como Harvard ou o MIT [Massachusetts Institute of Technology], que são universidades pequenas, focadas, com até $35 \mathrm{mil}$ estudantes, com universidades como a USP. Pois além de ser um grande instituto de pesquisa, o mais importante do Brasil, a USP é a principal geradora de conhecimento em ciência, tecnologia e humanidades no País [M. A. Zago, reitor da USP] (DIAS, 2016).

Em que pesem as limitações e inadequações dos rankings mundiais de universidades, são inegáveis os resultados positivos apresentados pela Unicamp nos últimos anos, especialmente, considerando que são classificações relativizadas pela aplicação dos mesmos critérios a todas as universidades analisadas. Outro fato a ser considerado é que, de modo geral, as universidades mais antigas e tradicionais costumam ter melhor avaliação do que as mais jovens. [José Tadeu Jorge, ex-reitor] (JORGE, 2017).

O pró-reitor de Pesquisa, José Eduardo Krieger, lembra que a excelência que os rankings querem refletir, em geral, está associada a uma categoria de instituição específica: as universidades de pesquisa. Muito embora a USP concentre quase um 
quarto de toda a produção científica do País, ela não entra nesse grupo seleto. "Somos muito grandes, com uma atuação diversificada, em várias áreas do conhecimento, e as universidades de pesquisa são muito focadas", observa. "Para ter áreas de excelência, estando em um país periférico, com nível de investimento em pesquisa diferente de países como os da América do Norte e da Europa, o esforço é muito maior. E mesmo assim, nós temos áreas de excelência”, afirma (CAIRES, 2016).

Destaca-se, no último depoimento, a menção a um erro corrente nas comparações educacionais: a não inclusão de dados importantes que deveriam ser correlacionados com o desempenho: no caso, as diferenças do gasto com educação entre as instituições globais consideradas nos rankings $s^{8}$.

Em outros depoimentos, são analisados aspectos políticos relacionados com os rankings:

\begin{abstract}
Em âmbito nacional e mundial, são várias as instituições que se propõem a elaborar rankings: consultorias de orientação profissional e aconselhamento estudantil, jornais e institutos de pesquisa, por exemplo. "Sendo assim, é importante ter em mente que os rankings não são instrumentos neutros, mas sim construídos e utilizados intencionalmente, para fins e contextos específicos", alerta Solange Maria dos Santos, que é coordenadora de produção e publicação da biblioteca eletrônica virtual de periódicos SciELO. Ela exemplifica que um ranking produzido por uma instituição com fins lucrativos, ainda que produzido com rigor metodológico, pode sofrer pressão ou influência quanto às fontes a serem consideradas para a coleta de dados e também quanto ao peso ou à inclusão de indicadores mais voltados às necessidades ou expectativas do mercado de trabalho. "Ou, ainda, indicadores nos quais universidades privadas mais se destacam, já que a instituição responsável por produzir o ranking precisa obter lucro que justifique continuar a publicá-lo.” (NAOE, 2016a).
\end{abstract}

Para Axel-Berg, um ranking verdadeiramente universal de "qualidade" não seria possível produzir, já que se trata de "um conceito multi-facetado aplicado a instituições dinâmicas e complexas". "Rankings representam a aplicação de uma lógica de negócios para uma área em que isso não é a mais adequada forma de avaliação", teoriza (DIAS, 2016).

Como se pode observar acima, as críticas aos rankings sempre são realizadas não pelos jornalistas autores das matérias, mas por autoridades, pesquisadores e funcionários especializados das universidades. Desta forma, as mídias utilizam o clássico argumento retórico de autoridade para destacar as opiniões. Os que falaram foram reitores na época (Marco Antônio Zago), ex- reitores (Jorge Tadeu Jorge), pró-reitores (Eduardo Krieger), professor sênior e expresidente de Associação dos Docentes da USP (Otaviano Helene), entre outros.

Também argumentaram doutores, mestres e funcionários da biblioteca. Por exemplo, a especialista Solange Maria dos Santos é apresentada no Jornal da USP em diversas matérias, informando que ela defendeu tese de doutorado na Escola de Comunicações e Artes (ECA) da

\footnotetext{
${ }^{8}$ É corrente também, as comparações internacionais ignorarem diferentes características socioeconômicas dos estudantes, apesar de corroborada sua influência no desempenho dos mesmos.
} 
USP ${ }^{9}$. Seu trabalho venceu o Prêmio Capes de Tese em 2016 e tratou do desempenho das universidades brasileiras nos principais rankings internacionais. Ela também é coordenadora de produção e publicação da biblioteca eletrônica virtual de periódicos SciELO (NAOE, 2016a).

É mencionado também Justin Hugo Axel Berg, quem fez uma dissertação de mestrado no Instituto de Relações Internacionais da $\mathrm{USP}^{10}$ e atualmente é pesquisador do Projeto Métricas. Outra fonte é Anderson Santana, chefe da Divisão de Gestão de Projetos do Departamento Técnico do Sistema Integrado de Bibliotecas (SIBi) da USP (CAIRES, 2016).

No Jornal da Unicamp também é mencionada Sabine Righetti, quem participa da elaboração do Ranking Universitário do Jornal Folha de S.Paulo (RUF) e defendeu tese sobre rankings nessa instituição ${ }^{11}$ (ORSI, 2017).

\section{Ações decorrentes dos rankings}

Há várias menções nos materiais analisados a não realização de ajustes das instituições aos rankings, como se pode notar na fala do reitor da USP em evento internacional na Colômbia:

[...] embora devamos reconhecer a contribuição das classificações globais para a melhoria da qualidade das instituições de ensino superior, elas não podem substituir o planejamento e avaliação local, que enfatiza o impacto nacional e regional das universidades latino-americanas. (REITOR..., 2016).

Na mesma linha de argumentação manifestou-se Solange Santos:

[...] O aperfeiçoamento das universidades, segundo Solange, não está em modificar o valor de um indicador para melhorar seu posicionamento em um determinado ranking, mas em promover práticas e culturas que melhorem seu desempenho frente à sua missão institucional, fundamentada no tripé ensino, pesquisa e extensão. O que não significa que os resultados expostos pelos rankings devam ser ignorados por completo (USP..., 2016).

Concomitantemente, houve a criação do Escritório de Indicadores de Desempenho na USP, em 2018 e do Projeto Métricas que envolve as três universidades estaduais paulistas, em 2017, (USP..., 2017), que embora não estão explicitamente atrelados aos rankings acadêmicos internacionais, permitem tecer hipóteses que relacionam os dois fatos, dado seus objetivos de tratar de indicadores e de comparações internacionais.

\footnotetext{
${ }^{9}$ SANTOS, Solange Maria dos. O desempenho das universidades brasileiras nos rankings internacionais: áreas de destaque da produção científica brasileira. 2015. Tese (Doutorado em Cultura e Informação) - Escola de Comunicações e Artes, Universidade de São Paulo, São Paulo, 2015.

${ }^{10}$ AXEL-BERG. Justin Hugo. Competing on the world stage: the Universidade de São Paulo and global university rankings. 2015. Dissertação (Mestrado em Relações Internacionais) - Instituto de Relações Internacionais, Universidade de São Paulo, São Paulo, 2015.

${ }^{11}$ RIGHETTI, Sabine. Qual é a melhor?: origem, indicadores, limitações e impactos dos rankings universitários. 2016. Tese (Doutorado) - Instituto de Geociências, Universidade Estadual de Campinas, Campinas, SP, 2016. Disponível em: http://www.repositorio.unicamp.br/handle/REPOSIP/321911.
} 


\section{Considerações finais}

Os usos dos rankings, nas mídias das duas instituições, ratificam a influência da escala global na educação superior ao ecoarem os resultados obtidos pelas universidades nas suas estratégias de divulgação. O caso dos resultados do Times Higher Education são exemplo de como as medidas de excelência selecionadas por um Jornal inglês, criador do ranking, adquirem ou até ultrapassam as políticas regionais, nacionais e estaduais de educação superior chegando ao nível institucional que as aceitam e reproduzem à comunidade acadêmica e à sociedade, naturalizando assim os valores que os seus indicadores priorizam e influindo nas prioridades das universidades no mundo todo.

As matérias analisadas exemplificadas com alguns trechos mostram, reforçam e divulgam o paradigma da competitividade entre as universidades, que convivem com a contradição proposta por uma de suas missões: a cooperação interinstitucional nacional e internacional. Assim, as universidades devem competir e cooperar na educação superior globalizada.

Diversas subidas e descidas em diversos rankings são manchetes das mídias universitárias assim como em outros veículos de informação massiva. Comparações entre instituições, blocos e regiões contribuem para destacar as instituições e seus resultados, num universo de variados rankings nos quais sempre haverá alguma posição alcançada em algum deles, digna de ser notícia. Ignoram-se os contextos nacionais e locais e suas prioridades, assim como algumas missões das universidades que estes lhes incumbem.

Comemoração pelos resultados é um uso frequente dos resultados dos rankings, como foi mostrado, o que contribui para o reforço e/ou a legitimação da universidade, o qual nos últimos anos é extensivo à ciência e à educação públicas, num contexto de questionamentos e ataques de setores da sociedade. Em algumas ocasiões, a comemoração é relacionada à trajetória da instituição ou a políticas públicas ou institucionais de longa data, que parecem contrapor o suposto "sobe e desce" anual. Ainda, ao autoelogio contrapõem-se leituras críticas dos rankings e, especialmente, de critérios de medição uniformizados e indicadores, por parte de autoridades de instituições e de acadêmicos que os estudam, tentativa louvável dada a complexidade da temática.

No período analisado verificou-se mudança nos usos dos rankings, se no começo eles eram usados mais para legitimação, posteriormente começaram a aparecer mais matérias críticas.

Quanto às duas instituições, verificou-se também maior quantidade de matérias sobre rankings na USP do que na Unicamp. Os dirigentes de ambas as instituições manifestaram-se 
nas mídias acerca da independência dos rankings no desenvolvimento institucional, embora houvesse a criação de ações coordenadas que mostram políticas cooperativas visando à otimização da coleta de dados, que poderiam compor indicadores dos rankings.

A pesquisa em andamento continuará com análise de documentos e entrevistas com atores institucionais visando completar e aprofundar outros aspectos do uso dos rankings acadêmicos tentando minimizar as limitações desta indagação.

\section{Referências}

ALTBACH, Philip. The past, present, and future of the research university. In: ALTBACH, P.; SALMI, J. (org.). The road to academic excellence: the making of world-class research universities. Washington: The World Bank, 2011. p. 11-32.

ALVES FILHO, Manuel. Unicamp lidera ranking QS Brics entre as universidades brasileiras. Portal da Unicamp, Campinas, 23 nov. 2017a. Disponível em:

https://www.unicamp.br/unicamp/noticias/2017/11/23/unicamp-lidera-ranking-qs-brics-entreuniversidades-brasileiras. Acesso em: 15 jul. 2020.

ALVES FILHO, Manuel. Unicamp mantém posição no ranking global de universidades. Portal da Unicamp, Campinas, 5 set. 2017b. Disponível em:

https://www.unicamp.br/unicamp/noticias/2017/09/05/unicamp-mantem-posicao-no-rankingglobal-de-universidades. Acesso em: 15 jul. 2020.

BARREYRO, Gladys Beatriz. O discurso da qualidade da educação superior e seu desdobramento em políticas globais, regionais e nacionais. Tese (Livre Docência) Faculdade de Educação, Universidade de São Paulo, São Paulo, 2017.

BARREYRO, Gladys Beatriz. A avaliação da educação superior em escala global: da acreditação aos rankings e os resultados de aprendizagem. Avaliação, Campinas, v. 23, n. 1 p. 5-22, 2018. Disponível em:

https://www.scielo.br/j/aval/a/fJQqv3tn9HzJmqS8KRJTnYJ/?format=pdf\&lang=pt. Acesso em: 15 jul. 2020.

BARREYRO, G. B.; FERREIRA, F. B. Internacionalização: universidades de classe mundial e rankings acadêmicos. In: OLIVIERA, J. F.; LIMA, D.C.B.P (org.) Educação Superior e PNE (2014-2024): expansão e qualidade em questão. Brasília: ANPAE, 2019. p. 155-171.

BRITO, Carina. USP ocupa $10^{\circ}$ lugar entre as melhores universidades do Brics. Jornal da USP, São Paulo, 20 jul. 2016a. Disponível em: http://jornal.usp.br/universidade/usp-ocupa10o-lugar-em-ranking-de-universidades-dos-brics/. Acesso em: 15 jul. 2020.

BRITO, Carina. USP conquista primeiro lugar entre universidades latino-americanas. Jornal da USP, São Paulo, 14 jun. 2016b. Disponível em:http://jornal.usp.br/universidade/uspconquista-primeiro-lugar-entre-universidades-latino-americanas/. Acesso em: 15 jul. 2020.

CAIRES, Luisa. Indicadores de pesquisa em rankings podem encobrir distorções. Jornal da USP, São Paulo, 7 out. 2016. Disponível em: http://jornal.usp.br/universidade/indicadoresde-pesquisa-em-rankings-podem-encobrir-distorcoes/. Acesso em: 15 jul. 2020. 
CALDEIRA, Cinderella. USP se mantém entre as melhores universidades. Jornal da USP, São Paulo, 18 mar. 2014a. Disponível em:http://espabe.uspnet.usp.br/jorusp/?p=34829. Acesso em: 15 mar. 2021.

CALDEIRA, Cinderella. A universidade em alta nos rankings. Jornal da USP, 20 out. 2014b. Disponível em: https://espaber.uspnet.usp.br/jorusp/?p=37780. Acesso em: 15 jul. 2020.

CASTRO, Thiago. Pela $4^{\text {a }}$ vez, USP é a melhor no Ranking da Folha. Jornal da USP, São Paulo, 21 set. 2015. Disponível em: https://espaber.uspnet.usp.br/jorusp/?p=48034. Acesso em: 15 jul. 2020.

DALE, Roger. Globalisation, knowledge economy and comparative education. Comparative Education, London, v. 41, n. 2, p. 117-149, 2005.

DALE, Roger. Os diferentes papéis, propósitos e resultados dos modelos nacionais e regionais de educação. Educação \& Sociedade, Campinas, v. 30, n. 108, p. 867-890, 2009.

DIAS, Hérika. Não vamos tomar nenhuma medida para melhorar nos rankings. Jornal da USP, São Paulo, 26 out. 2016. Disponível em: http://jornal.usp.br/universidade/nao-vamostomar-nenhuma-medida-para-melhorar-nos-rankings/. Acesso em: 15 jul. 2020.

ERKKILÄ, Tero. Global university rankings, transnational policy discourse and higher education in Europe. European Journal of Education, Paris, v. 49, n. 1, p. 91-101, 2014. Disponível em: https://onlinelibrary.wiley.com/doi/epdf/10.1111/ejed.12063. Acesso em: 17 set. 2019.

HARVEY, Lee. Editorial. Rankings of higher education institutions: a critical review. Quality in Higher Education, Abingdon, v. 14, n. 3, p. 187-207, nov. 2008.

HAZELKORN, Ellen. Os rankings e a batalha por excelência de classe mundial: estratégias institucionais e escolhas de políticas. Revista Ensino Superior Unicamp, Campinas, n. 1, p. 43-64, 2010. Disponível em:

http://www.gr.unicamp.br/ceav/revistaensinosuperior/ed01_maio2010/pdf/Ed01_marco2010_ ranckings.pdf. Acesso em: 10 out. 2018.

HEBMÜLLER, Paulo. Em quinto lugar no planeta. Jornal da USP, São Paulo, 18 nov. 2014. Disponível em: https://espaber.uspnet.usp.br/jorusp/?p=38377. Acesso em: 15 jul. 2020.

JORGE, José Tadeu. Crise e oportunidade. Portal da Unicamp, Campinas, 27 jul. 2017. Disponível em: https://www.unicamp.br/unicamp/noticias/2017/07/27/crise-e-oportunidade. Acesso em: 15 jul. 2020.

LAUS, Sonia Pereira; MAGRO, Dalva. Os rankings acadêmicos internacionais: gênese e relevância. Repositório Institucional-UFSC, Florianópolis, 2013. Disponível em: https://repositorio.ufsc.br/bitstream/handle/123456789/113139/2013212\%20$\% 200$ s\%20rankings\%20acad\%c3\%aamicos\%20internacionais.pdf? sequence $=1 \&$ is Allowed $=$ y. Acesso em: 10 nov. 2018.

LEITE, Denise; GENRO, Maria Elly Herz. Avaliação e internacionalização da educação superior: Quo vadis América Latina? Avaliação, Campinas, Sorocaba, v. 17, n. 3, p.763-785, nov. 2012. Disponível em: http://www.scielo.br/pdf/aval/v17n3/a09v17n3. Acesso em: 18 nov. 2018.

NAOE, Aline. Rankings oferecem retrato importante, mas incompleto da Universidade.

Jornal da Usp, São Paulo, 18 nov. 2016a. Disponível em:

http://jornal.usp.br/universidade/rankings-oferecem-retrato-importante-mas-incompleto-dauniversidade-2/. Acesso em: 15 jul. 2020. 
NAOE, Aline. Excelência nos cursos de humanas atrai estrangeiros para a USP. Jornal da USP, São Paulo, 1 jun. 2016b. Disponível em:https://jornal.usp.br/universidade/excelencianos-cursos-de-humanas-atrai-estrangeiros-para-a-usp/. Acesso em: 15 jul. 2020.

ORSI, Carlos. Ranking destaca ensino e pesquisa. Portal da Unicamp, Campinas, 30 set. 2015. Disponível em:http://www.unicamp.br/unicamp/noticias/2015/09/30/ranking-destacaensino-e-pesquisa. Acesso em: 15 jul. 2020.

ORSI, Carlos. Pesquisa pioneira revela limitações e impactos de rankings universitários. Portal da Unicamp, Campinas, 13 mar. 2017. Disponível em:

https://www.unicamp.br/unicamp/ju/noticias/2017/03/09/pesquisa-pioneira-revela-limitacoese-impactos-de-rankings-universitarios. Acesso em: 15 jul. 2020.

ORSI, Carlos. THE: Unicamp é $2^{\text {a }}$ melhor da AL. Jornal da Unicamp, Campinas, 7 jul. 2016. Disponível em:http://www.unicamp.br/unicamp/noticias/2016/07/07/unicamp-e-2amelhor-da-al. Acesso em: 15 jul. 2020.

PILATTI, Luiz Alberto; CECHIN, Marizete Righi. Perfil das universidades brasileiras de e com potencial de classe mundial. Avaliação, Campinas; Sorocaba, v. 23, n. 1, p.75-103, mar. 2018. Disponível em: http://www.scielo.br/pdf/aval/v23n1/1982-5765-aval-23-01-00075.pdf. Acesso em: 18 nov. 2018.

RANKING QS coloca universidades paulistas no TOP 10. Portal da Unicamp, Campinas, 18 out. 2017. Disponível em: https://www.unicamp.br/unicamp/noticias/2017/10/19/ranking-qscoloca-universidades-paulistas-no-top-10. Acesso em: 15 jul. 2020.

REITOR da USP ministra conferência em evento internacional na Colômbia. Jornal da USP, São Paulo, 11 jul. 2016. Disponível em: http://jornal.usp.br/universidade/reitor-da-uspministra-conferencia-em-evento-internacional-na-colombia/. Acesso em: 15 jul. 2020.

ROBERTSON, Susan; DALE, Roger. Critical cultural political economy of the globalisation of education. Globalisation, Societies and Education, Bristol, v. 13, n. 1, p.149-170, 2015.

ROBERTSON, Susan; OLDS, K. World university rankings: on the new arts of governing (quality). Centre for globalisation, education and societies. Bristol: University of Bristol, UK., 2011. Disponível em: https://susanleerobertson.files.wordpress.com/2012/07/2012robertson-olds-world-university-rankings.pdf. Acesso em: 23 jan. 2018.

SALMI, Jamil. The challenge of establishing World Class Universities. Washington, DC: The World Bank, 2009. Disponível em: http://siteresources.worldbank.org/EDUCATION/Resources/2782001099079877269/547664-1099079956815/547670-1237305262556/WCU.pdf. Acesso em: 28 out. 2018.

SANTOS, Poliana Pereira. Análise das matérias sobre rankings divulgadas nas mídias da USP e da Unicamp. TCC (Licenciatura em Ciências da Natureza) - Escola de Artes, Ciências e Humanidades, Universidade de São Paulo, 2018.

SANTOS, Solange Maria; NORONHA, Daisy Pires. O desempenho das universidades brasileiras em rankings internacionais. Em Questão, Porto Alegre, v. 22, n. 2, p. 186-219, 2016. Disponível em: https://seer.ufrgs.br/EmQuestao/article/viewFile/56213/37992. Acesso em: 12 dez. 2018.

SILVA JÚNIOR, João dos R. The New Brazilian University. A busca por resultados comercializáveis: para quem? São Paulo: Canal 6 Editora, 2017. 
STENSAKER, Bjørn; KEHM, Barbara M. Introduction. In: KEHM, Barbara M.; STENSAKER, Bjørn (ed.). University rankings, diversity, and the new landscape of higher education. Rotterdam: Sense Publishers, 2009. p. vii-xix.

THIENGO, Lara. Universidades de classe mundial e o consenso pela excelência: tendências globais e locais. 2018. Tese (Doutorado em Educação) - Universidade Federal de Santa Catarina, Florianópolis, 2018.

USP sobe 23 posições e alcança a melhor classificação no QS Ranking, Jornal da USP, São Paulo, 5 set. 2016. Disponível em: http://jornal.usp.br/universidade/usp-sobe-23-posicoes-ealcanca-a-melhor-classificacao-no-qs-ranking/. Acesso em: 15 jul. 2020.

USP, Unesp e Unicamp reavaliam seus indicadores de desempenho institucional._Jornal da USP. São Paulo, 8 dez. 2017. Disponível em: http://jornal.usp.br/universidade/usp-unesp-eunicamp-reavaliam-seus-indicadores-de-desempenho-institucional/. Acesso em: 15 jul. 2020.

VILLEN, Gabriela. Unicamp sobe no ranking QS. Portal da Unicamp, Campinas, 8 jun. 2017. Disponível em: https://www.unicamp.br/unicamp/noticias/2017/06/08/unicamp-sobeno-ranking-qs. Acesso em: 15 jul. 2020.

YAMAMOTO, Érika. USP é a primeira latino-americana no THE World University Ranking. Jornal da USP, São Paulo, 5 set. 2017. Disponível em: https://jornal.usp.br/institucional/uspe-a-melhor-latino-americana-no-the-world-university-ranking/. Acesso em: 15 jul. 2020. 